\title{
Jammin' an Ending: Creativity, Knowledge, and Conduct among Jazz Musicians
}

\section{MARK DOFFMAN}

\begin{abstract}
Research into musical creativity has hitherto involved highly disparate approaches and has taken place largely at the level of the individual. As a result, creativity has tended to be interpreted in terms of either expressive behaviour(s) in performance or ineffable innovation. In the meantime, however, a tranche of interdisciplinary research has moved towards a more collaborative understanding of creativity. With reference to that research, this article analyses the performance of a jazz standard played at a jam session in London. In exploring this unplanned moment of collaborative creativity, the study looks at the relationship between the mundane shaping of an ending and its occurrence within a cultural tradition that demands inventiveness on the part of performers. From an examination of the different sets of cultural knowledge on which musicians draw and an analysis of the momentary interactive conduct of the performers we obtain a view of creativity as an emergent amalgam - a shifting blend of knowledge and conduct that works to bring a song to a close.
\end{abstract}

The analysis presented here is of the final, fleeting moments of the performance of a jazz standard at a London jam session. The notion of examining the rather perfunctory ending of a tune may seem perverse. Compared with the virtuoso solo displays usually encountered in the central portions of an improvised standard, jazz endings, especially in the unstructured context of a jam, would appear to be particularly unspectacular examples of human creativity, the point at which any genuinely creative sense of musical endeavour collapses. But it is in that very collapse that the interest lies: what can we learn about creativity from an object of study that is seen in many ways as formulaic and therefore antithetical to being creative?

Although my focus here is on a modest slice of improvised music-making - about one minute of a performance - the intention is to make a broader point about musical creativity and, in particular, two central factors that allow for the creation of an ending: musical knowledge and conduct. Creativity and the wide range of phenomena it implicates have been studied across a variety of disciplines. These fields include social-psychological research into creativity, ${ }^{1}$ various strands of sociolinguistic work on interaction, ${ }^{2}$ and, most importantly, ethnographic, empirical, and theoretical work on musical performance and creative practice. ${ }^{3}$

1 Csikszentmihalyi, 'Society, Culture, and Person', 325-39; Gardner, Creating Minds; Sawyer and DeZutter, 'Distributed Creativity', 81-92.

2 See two pieces of work by Silverstein, 'The Improvisational Performance' and 'Indexical Order'.

3 See Deliège and Wiggins, Musical Creativity, and two key ethnographic texts on jazz performance: Berliner, Thinking in Jazz, and Monson, Saying Something. 
In current music research, as Eric Clarke has observed, the examination of creativity has been fractured, either concentrating on its very finest gradations (that is, in terms of expressive detail) or, at the other end of the spectrum, examining creativity (with a particularly large and florid ' $\mathrm{C}$ ') as a high cultural imperative. ${ }^{4}$ Furthermore, the tendency has been to view creativity largely in terms of individual authorship. This article moves towards an understanding of creativity - considered both as specific real-time 'output' and as part of a larger cultural ideology - that is firmly located at the level of the group. Two aspects of group performance that underpin creativity are emphasized. These are, firstly, the way in which musical knowledge of various kinds is deployed in the creation of an ending (the knowledge in question being of the practical, often tacit, kind that musicians bring to performance) and, secondly, the conduct of the players as they attempt to manage the performance. Conduct is here an important term in the theorizing of musical interaction and creativity, since it implies both the management of performance and the presence of a performance ethic. Although improvised music bears many of the same interactive imprints as, say, an informal conversation, there is a heightened communicative rationality at work, and musical conduct is a vital part of musicians' striving for coherence in the risky environment of live performance.

\section{Methods and approach}

The recording and analytical methods used here emerge from approaches to the investigation of 'real world' music performance developed at the Open University as part of the 'Experience and Meaning in Music Performance' project (EMMP, 2005-8) led by Martin Clayton. Central to this method was the integration of fine-grained audio-visual data analysis with more conventional ethnographic approaches, such as participant observation and interview. ${ }^{5}$ The performance data for this article came from a recording of a jam session. The visual data were captured by two tripod-mounted video cameras, while the audio component of the performance was recorded simultaneously in multi-track to a laptop PC. The recording of separate audio and video streams allowed for subsequent detailed analysis of the performance as it unfolded. The video was analysed with The Observer behavioural analysis software, ${ }^{6}$ while the audio recording of the performance was transcribed with the assistance of Transcribe software.

The case study approach taken here makes use of EMMP methodology to present a detailed analysis of a 'slice' of performance, in a manner analogous to various kinds of sociolinguistic work on interaction that code self-contained stretches of dialogue in ways

4 Clarke, 'Creativity in Performance', 157.

5 Further information on this project, funded by the UK Arts and Humanities Research Council, can be found at the 'Experience and Meaning in Music Performance' website <http://www.open.ac.uk/Arts/experience/index.html>.

6 The Observer, a behavioural analysis programme, allows video material to be uploaded into the programme, coded, and then analysed. The video was coded according to a number of conditions - by participant, gaze patterns, and bodily or instrumental movement patterns. These conditions were then time-coded within the video segment into a database from which descriptive statistics could be obtained. This is an intensive analytical process: less than a minute of video will tend to yield a considerable number of coded behaviours. 
that reveal larger social processes at work. A case study is appropriate for data-rich environments such as music performance, in which an extract can yield considerable insight into musicians' conduct and their interactive processes. By complementing this detailed analysis with the participants' own observations about their performance, we obtain a 'thick', empirically grounded description of a 'thin' slice of humanly organized sound. The case in question here is the ending of the jazz/pop standard 'Sunny', played by musicians attending a public jam session at the Spice of Life pub in Soho, central London.

The organizers of the jam session and the music promoter at the venue had been contacted prior to our visits to the sessions, ${ }^{8}$ and permission was granted to make an audiovisual recording of the performance. Permissions were also obtained from the individual musicians themselves. Subsequently, broad-based and semi-structured interviews were conducted with a number of those who had performed at the session, and three of them were shown clips of the endings of particular numbers (including the one analysed in detail below) and invited to comment both on their individual practice in closing the tunes and their understanding of the interactive dynamics at work between performers in these moments. ${ }^{9}$

\section{Creativity}

Across a range of research on creativity a number of recurrent themes can be identified, and the concern here is with two such central issues concerning music performance and creativity. The first, implicit in the focus of this article, is the understanding of creativity as a collaborative, emergent social process. While few scholars nowadays would deny that creative work needs to be conceived of, at least at some level, as social, there is still a considerable and lingering attachment to the idea of creativity as inherently individual. Clarke has commented on a similar perspective in (largely cognitive) research into the nature of performance creativity, which has tended to model improvised performance as an internally produced set

7 Although this case study is focused on the ending of a single number, its observations and conclusions are supported by prior examination of the endings of eleven of the fourteen numbers played at this session of 5 July 2009, and seven of twelve numbers played on 5 October 2009. My initial analysis involved: 1) creating a broad taxonomy of ending types that were being performed (these ending types - endings within the form of the number, through an extended 'tag', and with different degrees of finality of closure, and so on - are explored in further detail below); 2) investigating the genealogy of some of the numbers by comparing endings played at the session with endings from recorded performances; and 3) noting the interactional characteristics of each ending. This process, supplemented by interviews with some of the musicians involved, gave me a framework within which I could carry out the more detailed investigation of one particular ending with the confidence that it was not an 'outlier' within the session and that the information it yielded was broadly representative of the way in which musicians such as these shape the end of a tune.

8 In total, four recordings were made between July and October 2009 as part of a larger study. The bulk of this article is based on the first visit to these sessions on 5 July 2009.

9 This method of encouraging performers to reflect on a particular performance borrows loosely from protocol analysis, in which the participants 'think aloud' either during or after a task on which they are working. Retrospective 'thinking aloud', using video footage of the performance, allows musicians a much more deeply engaged reflection on what was happening at the time; clearly, in this instance, a commentary that was simultaneous with the performance would be impractical. See Ericsson and Simon, Protocol Analysis. 
of algorithms without full acknowledgement of the inherently social nature of improvised performance. ${ }^{10}$ The individualized conception of creativity seems particularly enduring within much Western music scholarship, its fundamental warrant being the notion of the single authorial voice.

The critique of the autonomous individual creator lying outside the sociocultural narrative is not new. Much sociological and psychological work stresses the systemic nature of being novel. The work of Howard Becker, which adopts a symbolic interactionist viewpoint, has examined a number of different art worlds, including jazz, in an attempt to lay bare any romantic assumptions of the lone genius. ${ }^{11}$ Meanwhile the work of Mihalyi Csikszentmihalyi, from a systems perspective, views the process of creativity as involving the individual creator, the knowledge domain from which the work develops, and the socioeconomic field in which the work is assessed; but while Csikszentmihalyi acknowledges the way that the 'social' presupposes and defines any creative act, he still views that act as decidedly individualist at the level of production. ${ }^{12}$ A number of research strands have since helped to shift the notion of creativity in various fields of performance, including jazz, away from this individual-centred perspective: these include work on the distributed nature of knowledge and cognition in team work, ${ }^{13}$ ethnographic studies of creative musical interaction, ${ }^{14}$ and recent studies that emphasize creativity as ordered through emergent, complex, and collaborative elements. ${ }^{15}$

But beyond their focus on individual production in performance, there is a second significant way in which the systemic perspectives are inadequate, and that is their concomitant tendency to view creativity as an extraordinary capacity outside of everyday competence. There is a real danger, as Clarke has pointed out, that too broad a notion of creativity lacks explanatory power. ${ }^{16}$ At the same time, however, if there is too radical a distinction between the everyday and the out-of-the-ordinary practice of creativity, we lose sight of the constant dialectic through which creativity arises: that between routine or mundane practices and innovation within a cultural field. The sociolinguist Michael Silverstein has theorized this dialectic between immediate performance and wider sociocultural conditions in his work on indexical order and metapragmatics in speech, ${ }^{17}$ work that has been influential in recent studies of jazz interaction. ${ }^{18}$ In a similar way, I wish to explore the manner in which musicians engage in the mundane making of an ending within a cultural context informed by an ideology of inventiveness. There are thus two potentially conflicting constraints on how to end a tune: on the one hand the weight of a radically inventive musical tradition and, on the other, a more conservative burden - the moral imperative towards good conduct in the

10 Clarke, 'Creativity in Performance', 170.

11 Becker, Art Worlds.

12 Csikszentmihalyi, 'Society, Culture, and Person'.

13 Hutchins, Cognition in the Wild.

14 Monson, Saying Something, 133-91, and Reinholdsson, Making Music Together.

15 Sawyer, 'Group Creativity', 148-66.

16 Clarke, 'Creativity in Performance', 157.

17 Silverstein, 'The Improvisational Performance of Culture', 265.

18 Monson, Saying Something, 189. 
moment that allows all concerned to come out of the risky business of performing with some dignity.

\section{Knowledge}

What sort of things do musicians need to know in the act of creating? Although the form of improvisation associated with jazz is usually seen in terms of players exercising their autonomy, improvisation more accurately occurs through degrees of heteronomy ${ }^{19}-$ the ways in which knowledge and musicians' interventions constrain, regulate, and indeed liberate one another.

Without attempting here a review of the social nature of knowledge, it might be useful to set out some of the pertinent perspectives on how and what musicians know in order to improvise. Lucy Green has identified a spectrum of learning that operates in popular music, and her distinction between 'conscious' and 'unconscious' approaches to learning emerges from a wealth of research in psychological studies that distinguish between tacit and explicit forms of knowledge. ${ }^{20}$ Both are heavily at work in the context of a jam session. In the present case study, just before the band begins the tune 'Sunny', the guitar player takes the bass player through the chord changes, simultaneously playing the chords and naming them, thus laying out the bare minimum of harmonic knowledge that the bassist will need. This awareness of chord sequences is part of the conservatory or self-directed training that musicians need to have mastered prior to any serious work on the jazz scene. The way in which musicians gain knowledge of chord changes or types of ending will differ from one individual to another, and has varied historically. Access has been more regulated and consistent since the widespread dissemination of Real Books in the early $1970 \mathrm{~s} .{ }^{21}$ On the one hand this cultural shift towards learning from texts rather than recordings has made a more extensive pool of tunes (with broadly correct harmonizations) available to musicians. At the same time it has led to a certain ossification of the repertoire: material that is left out of Real Books is much more likely to be ignored. And while such texts have allowed accurate harmonic knowledge of the repertoire to become more widespread, they do not necessarily solve the problem of congruence between players. As pianist SC remarks: 'The only problem is, different people learn different versions of tunes; I find that sometimes you turn up to a jam and you get

19 Peters, The Philosophy of Improvisation.

20 See Green, How Popular Musicians Learn, 60, and, for work on tacit knowledge, Reber, Implicit Learning, and Sternberg and Horvath, Tacit Knowledge.

21 Real Books are collections of jazz lead sheets that emerged in the 1970s, part of a tradition of un-copyrighted popular music texts known generically as Fake Books. Authorship of the original Real Book is uncertain, but is attributed to students at Berklee College of Music, Boston. While the original Real Books vols 1-5 remain outside copyright and are still sold 'under the counter', there are now competing, legal lead sheet compendiums such as the New Real Book series. British musicians have put out their own compendiums, which are drawn from the original Real Books, notably The Source ( $c 1981$ ), which combined much of the original series into one volume through print reduction, and the more recent and rather more imaginatively titled Satanic Changes, which performs a similar function. These collections of lead lines annotated with chord changes have had a considerable impact on jazz education and performance by providing a ready source of material for musicians to work from. See Kernfeld, 'Pop Song Piracy', 6-8. 
somebody playing some sort of weird substitutions which they've learnt from a different Real Book, or something. ${ }^{22}$ SC also comments on the way in which jam sessions seem, in his recent experience, to have become more restricted in terms of repertory:

It depends on the jam session, but sometimes there's a really limited number of tunes that people can actually call at a jam session, which I think is a shame. Either that or you have people reading it off their iPhone, which is OK, but it's not the same as having it memorized, really - well, as far as I'm concerned. ${ }^{23}$

Implicit in the above comment is the perceived need to develop a library of tunes within one's memory.

In Do You Know...? Robert Faulkner and Howard Becker explore the world of jazz repertories, highlighting the way in which a repertory is not just a knowledge base but becomes the fundamental focus for making one's way in the world of jazz. ${ }^{24}$ One can see this clearly at work in the context of the jam sessions examined in this study. The house band for the jam tended to choose a repertory centred on the compositions of the iconic players in jazz, in contrast to the jam proper, during which the majority of tunes tended to be staple fare from the American Songbook. ${ }^{25}$ The workings of musical knowledge, however, are evident not only in such representational schemata as chord symbols and musical formulas: musicians also possess le sens pratique. ${ }^{26}$ A comment from pianist HA exemplifies this: 'In terms of how to end [a tune], usually I follow a little bit first because I don't think I can push them into any direction. I think they can do it more than I can. If I try too hard, it won't sound good [...] so I will tend to follow what is happening. ${ }^{27}$ Here we have an illustration of tacit knowledge (albeit knowledge that can be reflected upon after the event), in which one of the musicians describes his understanding of how he contributes to the organization of the ending by sensing whether it is appropriate to lead or follow at that point. His role as pianist in part determines his understanding of how to proceed, but knowing 'what to do' also includes both the aesthetics of shaping an ending and his sense of his position and status as a player within the hierarchy of the scene.

While there will be considerable overlap between the knowledge of ending forms used by a rehearsed group and a group of jammers, the critical difference lies in the degree of preplanning that occurs. The jam session effectively frames the collaborative creativity: since it is understood by the players that heavily scripted endings will not work in this environment, the prevailing creative aesthetic tends to permit a degree of latitude and free play. When an ending is not planned in advance, jazz musicians rely on a stock of cultural models whose

22 Interview with pianist SC, 30 August 2010.

23 Interview with pianist SC, 30 August 2010.

24 Faulkner and Becker, Do You Know?

25 Typically venue promoters will have musicians booked for the jam session, usually a trio of piano, bass, and drums, which will act as 'house band' for the evening. Some or all of these players may, however, be replaced as other musicians get up to play.

26 Bourdieu, Outline of a Theory of Practice, 3.

27 Interview with pianist HA, 6 June 2010. 
basic types are made up of a further set of structural, temporal, and harmonic features. GB, a saxophonist, commented on the variability and viability of such models as he made the distinction between endings for show tunes (which make up the bulk of the standards repertoire) and numbers written by jazz musicians. ${ }^{28}$ In the former category it is much more usual to revert to one of the stock endings, which in his words 'just allows the band to tread water', whereas in the latter category it is more likely that the tune will possess a quite specific ending that one would be expected to know. He felt that to play a 'tag' or other stock ending on a jazz number (he gave Joe Henderson's 'Inner Urge', and Wayne Shorter's 'Speak No Evil' and 'Witch Hunt' as examples) 'would kind of be inappropriate [...] it would sound alien'. ${ }^{29}$ So, in the minds of players, different parts of the repertory may be associated with different degrees of scripting as the song is brought to an end.

Over the fourteen numbers played in the jam session in question, there was a clear division between these two types of ending: in show tunes or standards from the American Songbook the use of a 'tag' - the repetition, usually a number of times, of a single melodic phrase (and its underlying chord progression) or an extended improvisation based on the tune's final bars - and in jazz or blues numbers the use of simply the composed ending or cadence of the tune (or 'head') on its final return. Five out of six jazz numbers at the session and the three blues numbers were concluded within the head itself, whereas the numbers from the American Songbook all finished with an extended tag that merged into closure with a marked ritardando. The type of ending adopted is therefore not simply a matter of performance practicality but a question of preserving the generic identity of the piece.

A working knowledge of musical materials, however, is insufficient; also important is the way in which that knowledge is distributed and applied within the group. This is not simply a question of the sort of distributed cognition that Edwin Hutchins has examined: ${ }^{30}$ rather, it includes reflexive awareness on the part of participants about this distribution. Musicians need not only to know the 'what' of performance, but also to be sensitive to the character of the event, which will shape the application of their knowledge on any particular occasion. The subtleties of their knowing 'what to do when' do not constitute information that can be gleaned from formal study. Saxophonist GB, for instance, described how his knowledge of leading a group was something developed tacitly over time:

Nobody sat me down and said 'Oh, you've got to do this: blah, blah, blah'. I don't think they did. Well, put it this way - I learnt how to do that, or I learnt to be aware of that [leading a band] before I went to university [...]. I used to go to jam sessions frequently, many nights of the week, and you see different people and you see what works and what doesn't work. ${ }^{31}$

28 Interestingly GB used the term 'jazz standard' to refer to this latter category, when in fact many players would use that term to describe the former category (of show tunes or numbers from the American Songbook).

29 Both from an interview with GB, 23 August 2010.

30 Hutchins, Cognition in the Wild.

31 Interview with GB, 23 August 2010. 
This last comment leads into the second factor that enables musicians to collaborate in creating an ending - their conduct on the 'stand'. ${ }^{32}$

\section{Conduct}

I would like to begin by situating conduct in relation to interactive behaviours in performance. The aim here is to deploy methodologies concerned with interaction to provide an empirical basis for looking at conduct, a term that tends to be associated more with macrothan with micro-social studies.

Studies of creative interaction have made a significant contribution to our understanding of the ways in which creative processes are constituted in complex systems far removed from the autonomous art-object perspective. Such studies tend to apply descriptive methodologies to real-world performance. Across this spectrum of research lie ethnographic studies of jazz interaction, fine-grained studies of gestural and attentional behaviours, ${ }^{33}$ and investigations of the emergent dynamics of musical entrainment amongst musicians. ${ }^{34}$ This sort of research goes some way towards remedying a key lacuna that Keith Sawyer and Stacy DeZutter have identified in much work on creativity: the failure to analyse the detail of group interaction. ${ }^{35}$ Both their study and Sawyer's work more generally point towards new openings in the study of creativity. Proposing the term 'collaborative emergence' to describe situations in which the group work concerned is unpredictable in terms of outcome, Sawyer and DeZutter have used interaction analysis methodology to present a detailed dissection of an improvisational theatre performance. This form of analysis is a relatively recent interdisciplinary approach that has emerged from sociolinguistics, ${ }^{36}$ and has its roots further back in the work of social phenomenologists such as Alfred Schutz and George Herbert Mead. ${ }^{37}$

Two areas of interest to interaction researchers have been the use of gaze and gesture to coordinate the flow of utterances in face-to-face interaction. Research into gaze has been directed towards the ways it offers an index of accessibility and commitment to any ongoing interactions. Adam Kendon has systematically analysed the function of directed gaze in terms of the way in which it monitors - and thus also becomes a means of regulating the behaviour of others. ${ }^{38}$ The other significant area of research into non-verbal communication has focused on the use of gesture in encounters. A number of taxonomies of speech

32 'Stand' (an abbreviation of 'bandstand') is a term used by musicians to refer to the 'stage' area of a club, which need not be raised and, indeed, might be marked off from the rest of the seating only in an ad hoc manner.

33 See Clayton, 'Time, Gesture and Attention', 71, and Moran, Measuring Musical Interaction.

34 Entrainment is understood as a foundational process whereby independent rhythmic systems 'lock in' to one another. In recent research this theoretical concept has been applied to empirical work in music and social interaction. For an overview see Clayton, Sager, and Will, 'In Time with the Music', and for an explicit account of musical entrainment within jazz performance see Doffman, 'Feeling the Groove'.

35 Sawyer and DeZutter, 'Distributed Creativity', 81.

36 See, for instance, Goffman, Interaction Ritual and Behavior in Public Places.

37 Schutz, Collected Papers, vol. 2, p. 159, and Mead, Mind, Self, and Society.

38 Kendon, Conducting Interaction, 53. 
gesture (drawn notably from the work of David McNeill, and of Paul Ekman and Wallace Friesen) have been influential in the analysis of music performance. ${ }^{39}$ Within ethnographically based studies of communication in performance, ${ }^{40}$ and psychosocial research on gestural communication in music, ${ }^{41}$ the impact and meaning of bodily movement have been researched using classifications derived from the study of gesture in speech. In this study I borrow from interaction analysis methodologies (that is, the measuring of gaze patterns, body positioning, and gesturing with the musical instrument itself), but confine my analysis of communicative sound and bodily gestures to those that are directly involved in the creative management of the performance. So, unlike many studies of gesture and performance, mine is not concerned with communication that is overtly directed outwards to the audience, though it is fully recognized that the intercourse between players is unavoidably transmitted to the audience at some level. Rather my focus is on the way in which such interactive behaviours form a pattern of conduct, and it is by way of the notion of conduct that I relate the mundane creation evident in these jam sessions to the sense of jazz performance as part of a broader creative ideology.

Conduct emphasizes the moral imperative for musicians to pool their resources and collaboratively shape the performance. The intersubjective accomplishment of action in a jazz performance may be unpredictable, but there is no doubting the commitment to collective action. This does not mean that power and hegemony are not features of performance, but it does mean that there is an underlying communicative rationality (in the Habermasian sense) that prefigures conflict and contest. ${ }^{42}$ Forms of conduct become apparent in the momentary interactions of players, but emerge fundamentally from the constraints of the creative field in which they work. Conduct is used here also in a second and more clearly musical sense: the way in which musicians might organize and guide one another in their work. These two senses of the term are not mutually exclusive: the organization and management of others through the use of signs, sonic and visual, is intimately linked to the notion of conduct as an overarching way of being.

The theorization of social conduct has been explored as a site of regulation, training, and instrumental rationality. For Foucault, as a philosopher of power, the development of conduct occurs through various techniques of training and repetitive practice, ${ }^{43}$ and for Bourdieu, practice or conduct within a field is closely allied to the securing of status and power, as reflected in his work on cultural capital. ${ }^{44}$ Such rather pessimistic approaches to social conduct have been applied to the field of jazz, where the securing of prestige and power is understood as part of the struggle of working as a jazz musician. ${ }^{45}$ But while there

\footnotetext{
39 Ekman and Friesen, 'The Repertoire of Non-Verbal Behavior', 49; McNeill, Gesture and Thought.

40 Clayton, 'Communication in Raga Performance', 361.

41 Davidson, 'The Role of the Body', 235.

42 See Habermas's study of the groundings of social conduct and communication in On the Pragmatics of Communication, 183.

43 For a summary of Foucault's position on conduct see McFall, duGay, and Carter, Conduct, 88-119.

44 Bourdieu, Distinction.

45 Kirschbaum, 'Careers in the Right Beat', 187.
} 
may well be elements of the strategic and the instrumentally rational in musicians' dealings with one another, there are surely less abject dimensions to their creative practice. Mark Banks has pointed to Alasdair MacIntyre's work on social virtue as a more benign account of practice within a community (though MacIntyre is not fully optimistic about the scope for virtue in contemporary society). MacIntyre argues that practices such as jazz generate 'goods' that are both internal to the carrying out of the practice (in other words, they are obtainable solely and exclusively through its exercise) and external (in that they may be obtainable through that same practice but are equally obtainable through other practices). Some of the internal goods that Banks has identified within the practice of jazz include the creative fulfilment involved in performing and the feeling of community that jazz practice engenders; an external good, on the other hand, might be receiving payment, a common benefit of jazz performance but one that might equally be gained through any number of other occupations or practices. ${ }^{46}$

How musicians behave towards one another has a direct bearing on the outcome of the performance, as can be seen from the following analysis in which musical conduct, rather than knowledge alone, is the key to the band's ability to finish a song (more or less) together. In the following section I explore the jammed ending of 'Sunny' in some detail, and look at the ways in which musicians know about what they are doing and how they conduct themselves in the course of the creative process.

\section{Creating an ending in a jam session}

Within jazz practice the jam session has traditionally functioned as a place of musical development, social support, and career opportunity for musicians. ${ }^{47}$ As a performance mode it currently occupies a space somewhere between a formal public performance and the private, after-hours music-making of consociates, but its roots, certainly at the birth of bebop, suggest a much more private affair - 'an uncorrupted, unmediated, and uncommercial form of musical expression' - in which musicians sought escape from the pressures of the paid gig or concert stage. ${ }^{48}$ On the London scene jam sessions have developed into a hybrid kind of performance - one that is attended by audiences (that frequently pay) but whose incorporation of players from the floor, informality of presentation, lack of preparation, and paucity of payment place it at some distance from the concert or club date. ${ }^{49}$

46 Banks, 'MacIntyre, Bourdieu and the Practice of Jazz'.

47 For a symbolic interactionist perspective on jam sessions see Dempsey, 'Hook-Ups and Train Wrecks', 57-75.

48 Deveaux, Birth of Bebop, 204.

49 The distinction can be clearly seen at Ronnie Scott's Club, London, which currently hosts jam sessions in the main club space on Mondays to Thursdays after the main show. Entry to these late night sessions is free for Musicians' Union members and $£ 10$ for non-union members, about sixty to seventy per cent less than a ticket for the main show. At the time of writing I am aware of about fifteen venues across London that advertise themselves as 'jam sessions' on a regular or occasional basis. Typically these sessions are free or operate at an entry price well below the 'gig' price. 
The significance of jamming in the development of jazz reflects the nature of a music that demands interaction and a deft response to the momentary negotiations occurring in performance - hence a musical sensitivity that cannot be developed purely through the solipsistic routines of private practice. The jam session also allows for the invigoration of musical scenes through the coming together of players of different levels of experience and capacity, providing less experienced players with an opportunity to engage with their seniors. ${ }^{50}$ The benefits of legitimate peripheral participation, however, work both ways: the inclusion of younger players can also provide older musicians with new stimuli and refreshing encounters with new ideas communicated with vigour. ${ }^{51}$ As inexperienced players are inducted into the scene, the scene is disturbed, compromised, and challenged through different ways of playing, and more experienced players have to learn how to accommodate newcomers.

The venue for this jam session was The Spice of Life, a pub in Soho in the West End of London, which hosts a fortnightly Sunday afternoon session organized by Tomorrow's Warriors. ${ }^{52}$ The pub is a long-established music venue and holds regular jazz gigs. The jam sessions attracted a mixed audience of between twenty and thirty people, made up of not only musicians wanting to take part but also listeners taking the opportunity to hear Sunday lunchtime jazz at a modest price (entry was $\mathfrak{E} 3$ ). The format of the session followed the common model of a house band playing for about one hour, with the jam then being opened to musicians from the 'floor'. The session was ended by the return of the house band for a final set.

The performance whose ending is analysed here involved four musicians - a guitarist, a double bassist, a pianist, and a drummer. These players were of different levels of experience and status. The bassist is a well-known figure, who has enjoyed considerable success with a number of groups over the years; the guitarist, though an amateur musician, has been playing for a long time and is experienced as a 'gigging' performer. The pianist and the drummer, on the other hand, are both young players at the start of their careers: the pianist is a rather exceptional young musician who has been attending jams over a number of years, while the drummer came to the sessions as part of the Tomorrow's Warriors young musicians' project.

50 The notion of a scene is well understood by jazz musicians. It refers to a community of practice and practitioners framed by place, genre, and aesthetics. For an extensive ethnography of a music scene in New York see Jackson, 'Performance and Musical Meaning'.

51 'Legitimate peripheral participation' is the notion developed by Jean Lave and Etienne Wenger, in their work on communities of practice, to account for the ways in which beginners within a field of endeavour are inducted into the practices of the community. For a full account see Lave and Wenger, Situated Learning.

52 Tomorrow's Warriors is an educational charity set up by Dune Music, an independent jazz organization and record label. Tomorrow's Warriors runs workshops and jam sessions, and organizes concerts for young musicians. 


\section{'Sunny' - analysis of an ending}

A rather unremarkable tune, 'Sunny', is the basis for this analysis. It began its life as a pop song, written and performed by the late Bobby Hebb, a minor pop star working in the 1960s. The chord progression is given in Example 1 in its usual key of A minor. The song carries none of the weight associated in the jazz canon with the tunes of John Coltrane, Wayne Shorter, or Joe Henderson, but it has featured in the repertoires of many performers, including Nancy Wilson, Gene Harris, George Benson, Oscar Peterson, and Pat Martino.

\begin{tabular}{|l|ll|l|ll|}
\hline Amin7 & Gmin7 & C7 & Fmaj7 & Bmin7 $\quad$ E7 \\
\hline Amin7 & Gmin7 & C7 & Fmaj7 & Bmin7 $\quad$ E7 \\
\hline Amin7 & Gmin7 & C7 & Fmaj7 & B 7 & \\
\hline Bmin7, 5 & E7 $\$ 9$ & & Amin7 & E7 9 & \\
\hline
\end{tabular}

Example 1 Bobby Hebb, 'Sunny': chord progression. C 1965 Portable Music Co. Inc., USA. Administered by Campbell Connelly \& Co. Ltd for the UK, Australasia, Israel, South Africa, the Continent of Europe, and Eire. World excluding UK, Australasia, Israel, South Africa, the Continent of Europe, and Eire approved by Portable Music Co. Inc., USA. All rights reserved. International copyright secured. Used by permission.

In the moments before the performance of 'Sunny', there was some limited discussion. First, as mentioned earlier, the guitarist went through the chord sequence of the song with the bassist; this is standard practice among jazz musicians, and at that point it would be expected that the player in question would have the 'roadmap' secure in his head. The pianist and the guitarist then discussed who would play the head of the tune, and it was agreed that the pianist would play the 'in-head' and the guitarist the 'out-head'. ${ }^{53}$ Agreement was then reached on the tempo proposed by the guitarist, and finally the rhythmic feel of the piece was established: 'straight eighths' rather than 'swung. ${ }^{54}$ The way in which they would end the piece was not discussed. In the case of a reasonably well-known standard there is the tacit understanding that one of a relatively small number of endings will be used, but the decision concerning which one tends to be made in the moment. ${ }^{55}$ As will become clear in the analysis, the route through to the end of the song was not without incident in this performance, and the ending was not as clean or coherent as the players might have wished. It must be stressed, however, that, particularly in the context of a jam, it is the process rather than the product that is central for the musicians.

53 The 'in-head' refers to the initial playing of the melody prior to soloing, while the 'out-head' refers to the reiteration of the melody after the solos have been completed.

54 The rhythmic feel in most jazz performance is termed 'swung' to indicate the long-short relationship of each pair of quavers, but with the influence of Latin, funk, and rock, many tunes will be played in even quavers, hence with what players often call a 'straight eighths feel'.

55 There are a number of stock endings based on functional harmony that allow for a semi-controlled exit of the number. Commonly, musicians might make use of III-IV-II-V sequences that replace the final two bars of a number and can then be 'tagged' round a number of times. There are a number of variations on this approach, some of which entail harmonic substitutions. Certain endings have acquired names, for instance the 'Ellington' ending

Dueck, 'Jazz Endings' provides an ethnographic study of the musical rehearsal of a jazz ending. 


\section{Moments of an ending}

At the point when the sixteen-bar out-head begins after the sequence of solos, the band orients itself to prepare for the ending. In the following analysis I make use of a transcription of the final thirty-two bars of the performance, which comprises a full transcription of the guitar line and a rhythmic transcription of the piano, bass, and drums, along with a sketched mapping of the interactive conduct of the players. ${ }^{56}$ In this way the relationship between interactive gestures and musical cues is preserved. Included in the transcription are a number of key elements, significant in their contribution to the creative management of this ending. The transcription is not included in its entirety for economy of presentation, nor is it intended to be an exhaustive piece of performance analysis: the musical elements have been pared down to the minimum required to convey the narrative of the ending, and the paramusical gestures and gazing noted on the transcription are confined to those with a direct bearing on the management of the ending. Figure 1 displays the spatial layout of the musicians as they performed this number.
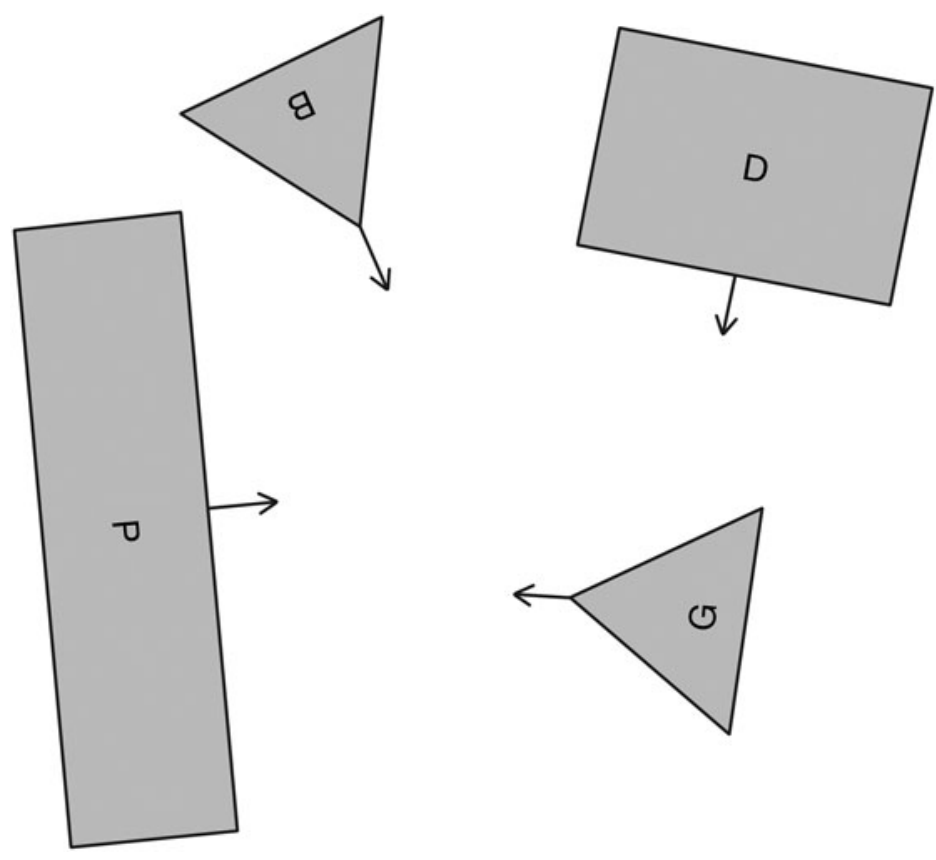

Figure 1 Relative layout of the musicians indicating the angle of their playing positions during 'Sunny'.

The ending of this song follows the orthodoxy of much jazz performance in that it can be segmented in the following manner: out-head, the sixteen-bar song structure; tag, the twobar harmonic sequence that is repeated after the sixteen-bar out-head is completed, using

56 Performance transcriptions vary according to the objectives of the research. Ingrid Monson's transcriptions of jazz performance (in Saying Something) do not always provide a fully notated account of the performance (some transcriptions make use of chord symbols rather than full notation), nor does her analysis include any substantial reference to the gestural aspects of interaction. 
the final two bars of the song form; close, the end of the tag moving into a ritardando and a loss of isochrony. ${ }^{57}$ In each of these moments the musicians rely on varying degrees of prior knowledge and interactive conduct as they move towards the end and 'negotiate' how this will occur. The first of these three segments is the only one that can be said to have a form that is definable independent of its sonic realization. With its pre-given sixteen-bar structure, the out-head has a written form that is readily available, entextualized within any number of jazz Real Books (for example, the guitarist was able to transmit its form to the bassist in the moments before the start of the performance). The tag, in this instance a repeating two-bar pattern that follows on from the head with a standard II-V cadence, similarly enjoys a pre-given structure, though the number of iterations this pattern will receive is not predetermined. While the transition from the out-head into the tag will be clear to the musicians, provided they are aware of the sixteen-bar form of the song or have a Real Book to hand, the transition from the tag to the close of the song becomes, by contrast, a much less certain affair. In the following sections, I look at each of these segments and the ways in which creativity is manifest through degrees of knowing and conduct between players.

\section{i) The out-head}

The out-head usually serves to consolidate the piece and involves a restatement of the tune played at the start. In the performance scrutinized here, the melody is played without undue embellishment, but with one or two modifications that indicate a complex kind of creativity at work. Musicians will sometimes make unusual note choices in a head for creative effect. For instance, saxophonist GB commented on his own rendition of another tune in this session, 'Yes and No' by Wayne Shorter, in which he drops just one note in the final 'A' section of the melody by a minor third; this could be heard as a mistake, but as he says 'it's a complete[ly] conscious thing, I'm thinking of it when I'm playing [...] in that instance. ${ }^{58}$ The effect is quite startling and signals the complex lineage of an otherwise incidental change to the melody: the drop by a minor third is a direct quotation from the version of this tune performed by Branford Marsalis, another great tenor player, on his album Random Abstract. ${ }^{59}$ While not 'innovative' practice according to definitions that prize individual authorship, this form of direct quoting is precisely what Ingrid Monson describes as 'intermusicality' - a longitudinal reworking of tradition but also an in-themoment act of creating anew, a process that Jason Toynbee has referred to as a form of social authorship. ${ }^{60}$

57 Out-head and tag are well established conventional terms within jazz discourse; I use the term close for the final segment to distinguish it from the overall ending of the song, but this term has no wide usage within the jazz community.

58 Interview with GB, 23 August 2010.

59 The tune originally appeared on Wayne Shorter's album Juju as 'Yes or No'. On Marsalis's album it is given what seems to have become its more widely accepted title, 'Yes and No'.

60 Toynbee, Making Popular Music. 


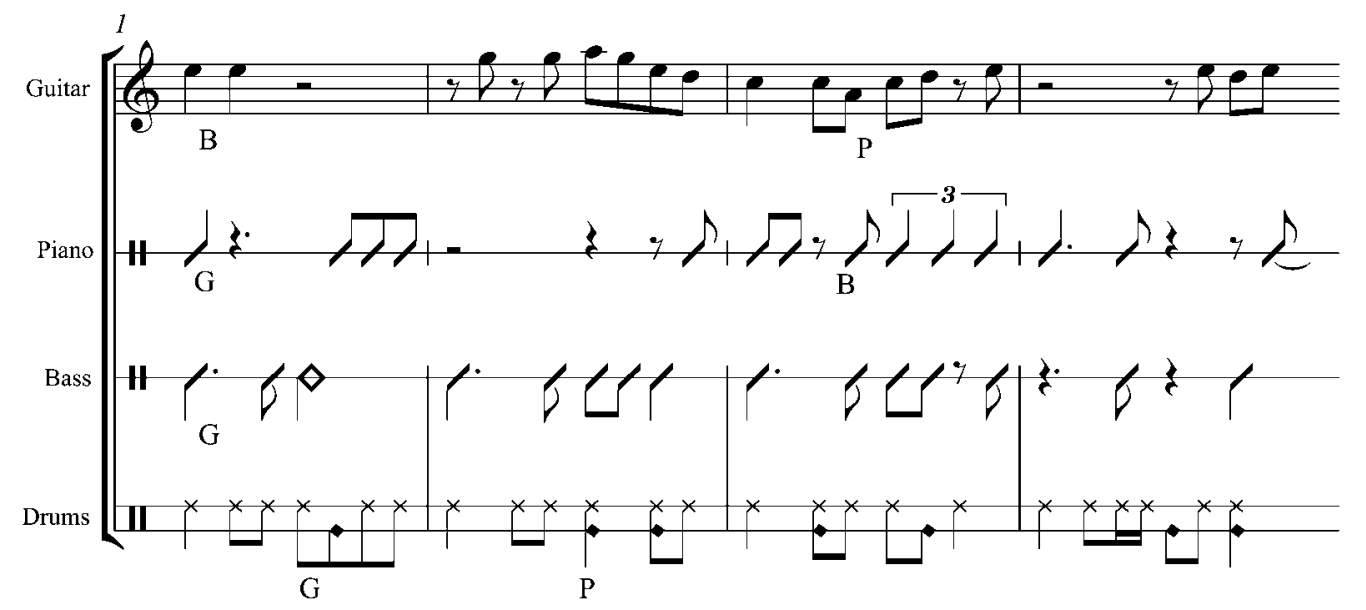

Example 2 The out-head: bars 1-4 showing guitarist, pianist, bassist, and drummer interactions. ${ }^{61}$

The embellishment within the final head on this version of 'Sunny' comes with no such retrospective acknowledgement of another performance, but the guitarist makes a number of subtle variations to the theme throughout. While this modest, perhaps mundane rephrasing of a mundane tune would be unremarkable to most jazz musicians, it is also an aspect of musical conduct that takes place not simply in the moment with other players but rather within the tradition. Even within the confines of a jam session musicians are reworking and reframing material, even if that material is little more than a stolid transcription of the original performance within a Real Book. The dialectical relationship between creativity as part of a larger cultural scheme and as mundane act seems evident here. Only within the larger framework of jazz culture do these relatively slight alterations and substitutions fall into place as a part of cultural endeavour, and only with the knowledge of prior versions do contemporary reworkings of melodies or solos achieve full significance. Gary Peters has commented that improvisation always enjoys a prehistory, 'an entanglement of the old and the new', and whether the reframing involves an active 'quotation' from a previous performance or simply the melodic reworking of a tired tune, jazz musicians sense some form of compulsion to add their contributions to the flux within the tradition. ${ }^{62}$

61 In the three sketched transcriptions of Examples 2, 3, and 4 gaze and gestural patterns are indicated by letters below the stave. The point at which the gazing musician initiates a gaze at another player is represented by a capital letter, and the musician to whom the gaze is directed is indicated by G (guitar), P (piano), B (bass), or D (drums). Conducting gestures, either in the form of a body move or the gestural movement of an instrument, are indicated by a capital letter enclosed in a square. The single instance of verbal interaction in these excerpts is shown by the letters PV (meaning verbal communication towards the pianist) enclosed within a square. The choice of letter indicates the player to whom the gesture is directed. For clarity, the point at which a gaze or gestural moment ends has been omitted.

62 Peters, Philosophy of Improvisation, 1. 
At this point in the ending, the pattern of interaction in terms of either gesture or gazing is at its most sparse compared to what happens in the tag and the close. As the out-head begins, the bassist, drummer, and pianist are all watching the guitarist, who earlier agreed to carry the tune. There is no overt bodily or instrumental gesturing to communicate with the other players, and only thirty-seven per cent of the gaze patterns throughout this sixteen-bar section are directed towards others in the group. ${ }^{63}$ Performance attention at this point appears to be directed more towards tacit individual knowledge than reflexive group conduct. The out-head is relatively risk free, and the three players, aside from the guitarist who carries the melody, are engaged in maintaining the groove and thus accompanying the soloist. The collaborative creativity at this point is therefore focused on support and the consolidation of the performance, before moving on to the riskier undertaking of ending the song.

\section{ii) The tag}

Once the band begins the repetitions of the two-bar tag, a wider field of possibilities starts to open up, and the musicians enter it not knowing which of these possible routes will be taken. The guitarist later reported that he had been expecting an ending whereby the tag would go round three or four times, and then probably finish with a ritard on the fifth bar.
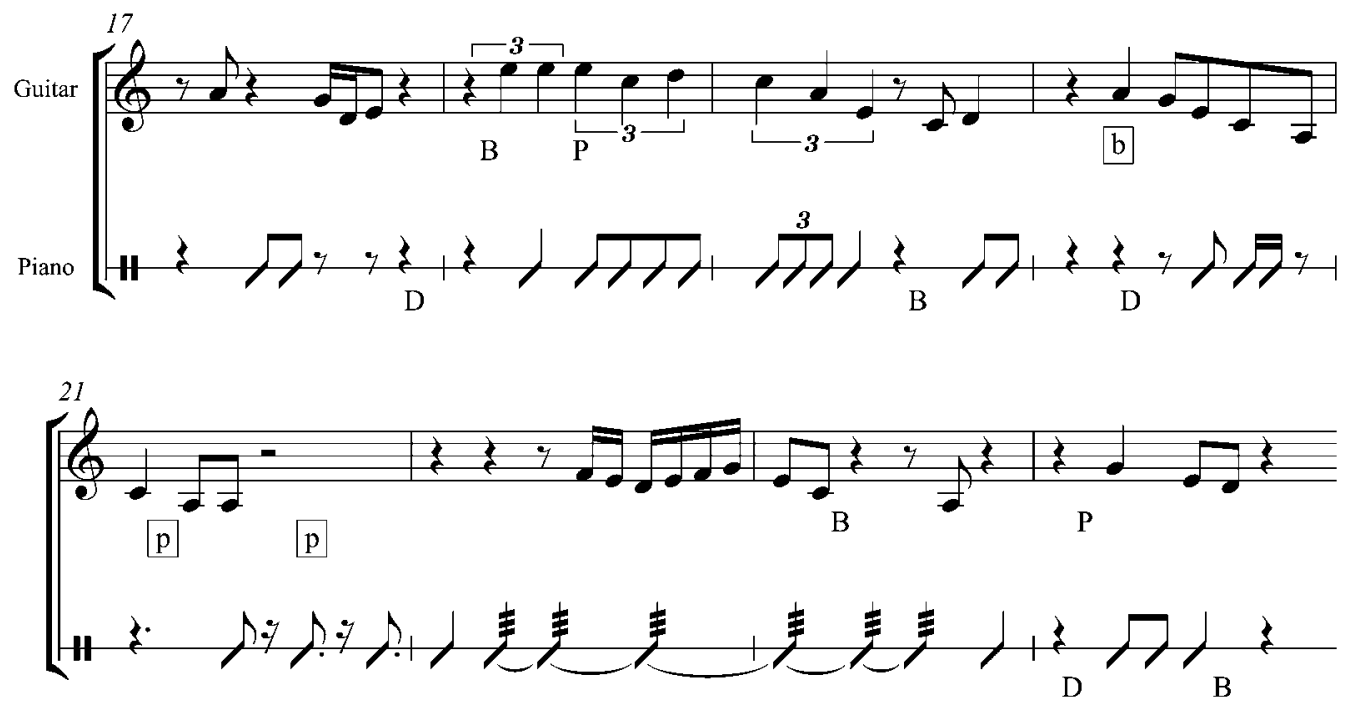

Example 3 The tag: bars 1-8 showing pianist and guitarist interactions.

63 This refers to the amount of gaze between players expressed as a percentage. Three gaze conditions were coded into The Observer for each musician - gazing at another musician, gazing at the audience, and gazing away. I use this descriptive statistic to show how, over the course of the entire ending, the pattern of gazing changes. If the players are not involved in the gazing summarized here, then they are looking at the audience or looking away from one another (this might include gazing at their instruments). 
The pianist, meanwhile, is clearly going for an extended tag. His accompanying style is highly rhythmic throughout the piece, but during the tag he breaks up the metre and rhythm such that the guitarist, taking on the role of leader, finds it hard to direct the ending through sonic means alone and begins to adopt a more overt strategy in 'conducting' the musicians towards the end of the number. One might construe these as manifesting two conflicting creative sensibilities. On the one hand, pianist SC is opting for an extended and quite intense 'outro': as he comments, 'When I'm playing it ['Sunny'], it generally tends to go on for a long time after, but I think he was trying to do a sort of "repeat the last phrase three times and end". But, probably because I was getting a bit self-indulgent, I just wanted to carry on. ${ }^{64}$ The guitarist $\mathrm{AE}$, on the other hand, who had initially expected a concise finish to the song, goes for a much more tightly managed ending. He describes the formulaic type of ending that a song such as 'Sunny' would often follow in these terms:

These things happen so much that there's a formula for it. Normally, either a phrase at the end is repeated three times, called a three-times ending - which everybody does and which is very boring - and I think in this instance I was trying to be safe and go for that $[. .$.$] and that didn't happen. { }^{65}$

This divergence in the apparent aims of the group - at least between the pianist and the guitarist - should not necessarily be seen as a creative failure. Improvised musical conduct is by nature inherently messy. What this does highlight, however, is the necessary but insufficient contribution of musical knowledge to improvisation. The comments of the pianist and the guitarist illustrate differences in conduct using a shared body of knowledge (the tagged ending). For the pianist, there was a sense of 'self-indulgence' as he pursued an extended ending, whereas the guitarist spoke of trying to be safe by wrapping up the song more formulaically. As the annotations to Example 3 show, over the duration of the tag the 'conducting' of the group changes. There is a greater degree of gaze between the performers than during the out-head: forty-eight per cent of all gazing is now directed towards other players. From this point the guitarist increasingly takes charge of the ending: the tag initially sees him trying unsuccessfully to engage with the pianist, and so his gazing towards the pianist at $\operatorname{tag}^{+5}$ is intensified by a proxemic move of his head and upper body towards the piano and a subsequent raising of the guitar headstock to signal his intention to end. At the same time the pianist's gaze is held either resolutely down towards the keyboard or towards the bass or drums, but not towards the guitarist. This fits with his apparent ambition to pursue an extended tag. The musical content at this point reinforces a sense of quite different creative aims. At $\mathrm{tag}^{+2-3}$ the triplet crotchets of the guitarist are suggestive of slowing down in an attempt to conclude, but it is clear from the semiquavers in $\operatorname{tag}^{+6}$, whose precise rhythmic focus is a little wayward, that he has since abandoned any attempt to close at

64 Interview with SC, 30 August 2010.

65 Interview with AE, 9 September 2010. 
this point. The pianist's extended tremolando on a chord at $\operatorname{tag}^{+5-7}$ likewise appears to deny the guitarist the possibility of closing the tune, by creating an animated pedal effect.

The gazing throughout the tag is dominated by the patterns of the two frontmost players, the pianist and the guitarist. Both the drummer and the bassist are watchful, but still tending to confine their gaze towards their instruments or away from the stand. The conduct of the players is therefore far from uniform. It is worth noting here that, although the bassist in this particular performance enjoys a higher status on the jazz scene than the other players, his role in managing the ending is minimal compared to that of the guitarist. This further underlines the notion of conduct in the moment: shaped by a less individualistic and more collaborative notion of creativity, the bass player's conduct is motivated by his role in the performance rather than his status on the scene.

\section{iii) The close}

In the closing moments of the piece the intensity of the interactions increases and the degree of mutual gazing between musicians is greater than at any other point during the three segments of the ending: the musicians direct sixty-three per cent of their gazing towards one another during this critical juncture. The sense of conducting the group falls almost entirely to the guitarist, whose gaze and gesturing become more animated as he attempts to manage the close. As can be seen in Example 4, the guitarist directs his attention mostly towards the pianist at $\operatorname{tag}^{+10-12}$, his gaze being accompanied by bodily movement and instrumental gesturing. In bar 11 he also calls out to the pianist 'Finish', which may be an instruction or a description, but either way increases the sense of urgency in his closing of the song. The use of a verbal instruction is unusual on the stand, and indicates the degree of close management that the guitarist clearly felt was necessary at that moment. The remainder of the group use gaze more sparsely, but all musicians at various points in these closing moments pay attention to the conducting behaviour of the guitar player. The nature of the collaboration at this moment is therefore rather different from that in improvisatory forums researched by others, in which there is relatively little overt sense of guiding the improvisation to its endpoint. ${ }^{66}$

At $\operatorname{tag}^{+12-13}$ the guitarist turns his attention to the drummer as he begins the final iteration of the tag prior to the close. At this point the guitar player marks beat 1 in bar 13. The song moves into the final phase of the ending, the close, marked by a strong ritard and a loss of isochrony. At close ${ }^{+1}$, as well as gazing towards the drummer, the guitar player uses the instrument effectively as a baton to conduct the ending, as the tempo decreases and the band slowly moves to silence. Jazz musicians routinely use this type of tempo change to signal the close of a song, but in this particular case two ritardandos are in evidence. The guitarist exhibits the strongest ritard at $c l o s e^{+1}$ after a downward melodic phrase, a motif which in itself might have suggested closure at $\operatorname{tag}^{+5}$ and which is now cut off sharply on the last quaver beat of the bar.

66 See, for instance, Sawyer and DeZutter, 'Distributed Creativity', 81. 

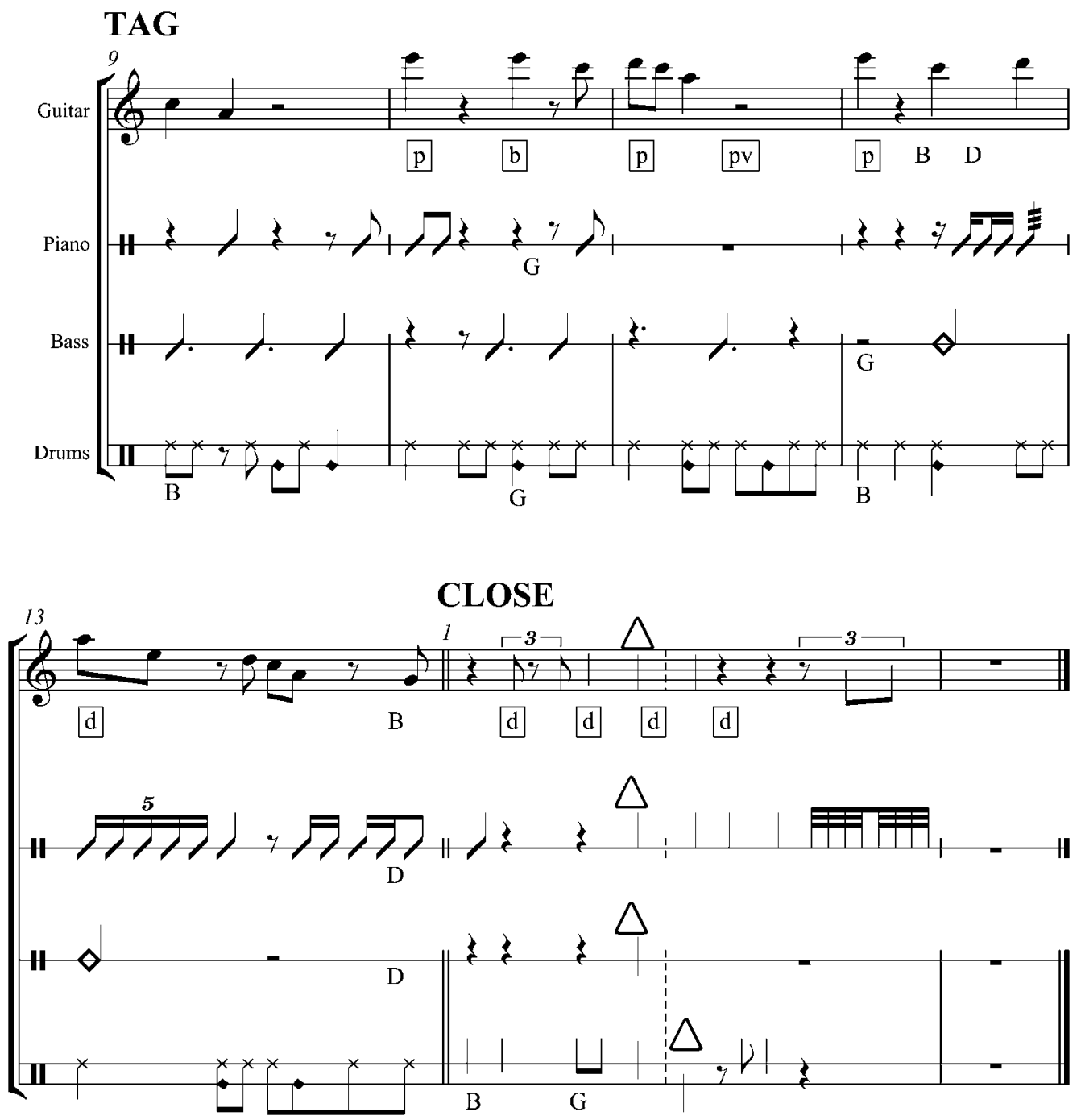

Example 4 Bars $9-13$ of the tag leading into bars $1-2$ of the close. ${ }^{67}$

By measuring the inter-bar interval (the temporal distance between the first beats of successive bars), one can see that the drummer and guitarist, from being in agreement about the length of each bar (i.e., from being in time), no longer share the same temporal frame at $c l o s e^{+1}$. The guitarist's inter-bar interval here represents an increase on the average a tempo bar length of around fifty-six per cent: in other words there is a change of tempo from around MM134 to around MM90. At the same time the drummer appears to slow to about MM122. During this bar, therefore, there is considerable breakdown in synchrony

67 Note in Example 4 that a double barline distinguishes bar 13 of the tag from the start of the close. Also note that a dashed barline and headless note stems are used at $c l o s e^{+2}$ to indicate a loosening of the metrical framework between the players. 
between the players. From the drummer's note choices in that bar it is clear that he is perceiving a shared beat (marked on Example 4 by a triangle symbol at $c l o s e^{+1-2}$ as beat 1 of $c l o s e^{+2}$ ) as a downbeat, whereas the guitar player, from the rhythmic choices he makes, appears to be interpreting this synchronous moment as beat 4 of $c l o s e^{+1}$. The bassist and the pianist reinforce this group synchrony by joining in with single notes at this point, but it is unclear whether they are cohering sonically or on the basis of visual cueing from the guitarist: certainly their gaze remains on the guitarist at this point. The relationship between knowledge and conduct is here at its most fractured. The drummer attempts to maintain a coherent metric framework as he slows down, drawing on his knowledge of the bossa nova beat, but the crucial synchrony that is achieved on the beat marked by the triangle on Example 4 is a product of conduct - the conduct of the guitarist in being clear with his signals and, just as important, that of the drummer in looking towards him. Although they might have been thinking in terms of different beat categories ('Are we on beat 1 or 4?'), the sounding result retains a coherence that is achieved through musical conduct, both in the practical sense of the musicians guiding each other (for instance in the guitarist's 'conducting' through the raising and lowering of his instrument) and in the broader sense of conduct as an ethical imperative to make musical actions work within the constraints of a creative field - within a tradition, in other words.

\section{Concluding discussion}

In the ending of this song the ordinary aspects of getting the work done and the ideological conditions of cultural endeavour are entangled: we see the musicians engaged in the practical, momentary work of stopping together and at the same time subordinating themselves to a creative ideology with its norms and rules for what is appropriate and how things should be done. The mechanisms for enacting these layered creativities are conduct and knowledge.

What emerges most clearly from an analysis of this ending is the changing relationship between conduct and knowledge. As the final part of this song develops, the relationship between pre-given knowledge and momentary conduct is altered. While there is never only conduct or knowledge, and while neither fully represents the 'moment' or the 'tradition' (conduct requires a knowledge of the way things should be and knowledge requires conduct of some kind to be implemented), the analysis shows a temporally dynamic relationship between the two. As the ending proceeds, the knowledge of chord sequences and tags is insufficient to achieve closure. So while the pianist and the guitarist in this performance had a shared knowledge of the chords to be used, their aims when it came to ending the song were clearly divergent (as the subsequent interviews with the players confirmed), and therefore a much greater use of gaze, bodily movement, and even language became necessary. We therefore see effectively two social mechanisms at work within the same stretch of musical material: one that is mobilized more actively when the sense of the immediate present is at its most acute, and one that is deployed when the performance conditions are perceived intersubjectively to be sufficiently stable for musicians to utilize their stocks of 
knowledge. Creativity therefore needs to be reimagined not only as a collaborative endeavour but also as a series of differentiated moments in which musicians draw on distinct resources (present conduct and prior knowledge) to fulfil the demand that they finish coherently.

There is a further sense of temporal change at work here though, namely timing and synchrony, and with it a contradistinctive form of knowledge. At the point when the pulsed groove ceases, that is at the close of the song, the sense of shared timing becomes radically disrupted. Up until the end of the tag the musicians rely not only on their knowledge of chords but also on the embodied knowledge of being in a groove together. This provides a metric framework through which shared knowledge and conduct can be articulated: the production of nods and gazes is constrained by collective entrainment just as much as the placement of chords and melody. However, isochrony and metrical alignment dissipate at the close, and it is at this point that coherence can be achieved only by means of intense and focused conducting. At this critical stage the guitarist most actively uses gaze and the movement of his guitar to lead the band, all the while knowing that, without the structuring properties of groove, this is the most risk-laden part of the song. The threat of failure is acute at the point when musical structure begins to dissipate, and so control (in the form of gaze) becomes more active.

Just as the distribution of creative control is not uniform over the period of this ending, neither is this control uniform or static throughout the group. The leadership of the guitar player is plain in this musical exchange, but this assumed role is not without its contradictions. Firstly the guitar player is leader by virtue of stage position and his inhabiting the role of soloist - a common alignment of the spatial and the sociomusical on a jazz stage - but this is not a usual position for guitarists. (If there was a saxophonist present, then he or she would be expected to guide the ending.) Secondly the guitarist might have experienced his own conducting role as being at odds with his position on the scene: that of a more occasional player rather than a full-time professional. His determination to close the song, his pronounced gesturing, and his use of language to achieve closure could at one level be interpreted as strong leadership, but might equally imply that he sensed his own lack of authority in this role. All this suggests that roles are not just inhabited by musicians, but also that they inhabit musicians. There is a certain governmentality at work here: on the one hand the player overtly inhabits a role by leading the rest of the group, while on the other hand he is obliged by the norms of the tradition to take on a powerful role whether he seeks it or not, hence internalizing the rules of the game.

I have summarized the distribution of creativity in this piece as varying over the time of the performance and between the consociates on this jam session. Creativity is also a messy composite of the immediate output of a performed ending and the creative ideologies at work in jazz. Michael Silverstein (whose work on metapragmatics was alluded to earlier) proposes a useful way of understanding this intertwining of the everyday and the ideological. The mechanism that allows the momentary, improvised performance of conversation to both shape and be shaped by cultural ideologies is the inherently indexical quality of language: in other words, meaning is generated not simply by indexical chains within sentences but by means of the indexical function of language towards its past and future contexts. This 
indexicality can be applied here. To return to one of the above examples, saxophonist GB alters one note by a minor third in the out-head of 'Yes and No'. That note in itself changes little of the melodic substance of the tune (the 'indexical chain' within it), but as a quotation from Branford Marsalis it points to a past musical context. It suggests a plural creativity at work: on the one hand a form of acceptable, mundane conduct within the improvisatory commitments of the moment, but on the other hand a musical decision that places this saxophonist within a tradition of knowledge and prior performance, while also making available for those present a new way of performing this head that might hitherto have remained unavailable. Conduct and knowledge are used here both to preempt the present performance context on the basis of past performances and, potentially, to shape knowledge and conduct in future performances.

Although creativity has been theorized as a system in which individuals create according to the rules and practices of the field in which they work, I have tried to develop this further in two key ways: firstly by emphasizing the collaborative endeavour in so much artistic practice, exemplified here by musicians at a jam, and secondly by suggesting that creating on the fly and a regime of creativity do not inhabit separate worlds but, rather, exist in a productive tension. It is only by attempting to make things work in the moment yet simultaneously within the larger framework of a tradition that we derive a full picture of what it means to jam an ending.

\section{Discography}

Hebb, Bobby. Sunny/Bread. 7" single, Philips 40365, 1966.

Marsalis, Branford. Random Abstract. LP, CBS 461067-1, 1988; CD, CBS 461067-2, 1988.

Shorter, Wayne. Juju. LP (mono/stereo), Blue Note BLP 4182 / BST 84182, 1964; CD, Blue Note CDP7 465142 , 1987.

\section{Bibliography}

Banks, Mark. 'MacIntyre, Bourdieu and the Practice of Jazz'. Popular Music 31/1 (2012), 69-86.

Becker, Howard. Art Worlds. Berkeley: University of California Press, 1982.

Berliner, Paul. Thinking in Jazz: the Infinite Art of Improvisation. Chicago: Chicago University Press, 1994.

Bourdieu, Pierre. Outline of a Theory of Practice, trans. Richard Nice. Cambridge: Cambridge University Press, 1977.

—. Distinction: a Social Critique of the Judgement of Taste, trans. Richard Nice. Cambridge, MA: Harvard University Press, 1984.

Clarke, Eric. 'Creativity in Performance'. Musicae Scientiae 19 (2005), 157-82.

Clayton, Martin. 'Communication in Raga Performance', in Musical Communication, ed. Dorothy Miell, Ray MacDonald, and David Hargreaves. Oxford: Oxford University Press, 2005. 361-82.

—. 'Time, Gesture and Attention in a Khyal Performance'. Asian Music 38/2 (2007), 71-96.

Clayton, Martin, Rebecca Sager, and Udo Will. 'In Time with the Music: the Concept of Entrainment and Its Significance for Ethnomusicology'. ESEM Counterpoint 1 (2004), 1-84.

Csikszentmihalyi, Mihalyi. 'Society, Culture, and Person: a Systems View of Creativity', in The Nature of Creativity, ed. Robert Sternberg. Cambridge: Cambridge University Press, 1988. 325-39.

Davidson, Jane. 'The Role of the Body in the Production and Perception of a Solo Vocal Performance: a Case Study of Annie Lennox'. Musicae Scientiae 5/2 (2001), 235-56.

Deliège, Irène, and Geraint Wiggins. Musical Creativity. Hove: Psychology Press, 2006.

Dempsey, Nicholas. 'Hook-Ups and Train Wrecks: Contextual Parameters and the Coordination of Jazz Interactions'. Symbolic Interaction 31/1 (2008), 57-75.

Deveaux, Scott. The Birth of Bebop: a Social and Musical History. London: Picador, 1997. 
Doffman, Mark. 'Feeling the Groove: Shared Time and Its Meanings for Three Jazz Trios'. PhD diss., Open University, 2008.

Dueck, Byron. 'Jazz Endings, Ideology, and Public Culture', unpublished paper, 2011.

Ekman, Paul, and Wallace Friesen. 'The Repertoire of Non-Behavior: Categories, Origins, Usage, and Coding'. Semiotica 1 (1998), 49-98.

Ericsson, K. Anders, and Herbert A. Simon. Protocol Analysis: Verbal Reports as Data. Cambridge, MA: Bradford Books / MIT Press, 1993.

Faulkner, Robert, and Howard Becker. Do You Know ... ? The Jazz Repertoire in Action. Chicago: University of Chicago Press, 2009.

Foucault, Michel. Discipline and Punish: the Birth of the Prison. London: Allen Lane, 1977.

Gardner, Howard. Creating Minds. New York: Basic Books, 1993.

Goffman, Erving. Behavior in Public Places. New York: The Free Press, 1963.

—. Interaction Ritual: Essay on Face-to-Face Behavior. New York: Pantheon Books, 1967.

Green, Lucy. How Popular Musicians Learn: a Way Ahead for Music Education. Aldershot: Ashgate, 2002.

Habermas, Jürgen. On the Pragmatics of Communication, trans. Barbara Fultner. Cambridge: Polity Press, 1998.

Hutchins, Edwin. Cognition in the Wild. Cambridge, MA: MIT Press, 1995.

Jackson, Travis. 'Performance and Musical Meaning: Analyzing "Jazz" on the New York Scene'. PhD diss., Columbia University, 1998.

Kendon, Adam. Conducting Interaction: Patterns of Behavior in Focused Encounters. Cambridge: Cambridge University Press, 1990.

Kernfeld, Barry. 'Pop Song Piracy, Fake Books, and a Pre-history of Sampling'. Paper presented at Copyright and the Networked Computer: a Stakeholder's Congress, University of California, 2003. <http://www.personal. psu.edu/bdk4/PREHISTORY.pdf $>$ (accessed 19 September 2011).

Kirschbaum, Charles. 'Careers in the Right Beat: US Jazz Musicians' Typical and Non-typical Trajectories'. Career Development International 12/2 (2007), 187-201.

Lave, Jean, and Etienne Wenger. Situated Learning: Legitimate Peripheral Participation. Cambridge: Cambridge University Press, 1991.

McFall, Liz, Paul duGay, and Simon Carter. Conduct: Sociology and Social Worlds. Manchester: Manchester University Press, 2008.

McNeill, David. Gesture and Thought. Chicago: Chicago University Press, 2005.

Mead, George Herbert. Mind, Self, and Society from the Standpoint of a Social Behaviorist. Chicago: Chicago University Press, 1967.

Monson, Ingrid. Saying Something: Jazz Improvisation and Interaction. Chicago: Chicago University Press, 1996.

Moran, Nikki. 'Measuring Musical Interaction: Analysing Communication in Embodied Musical Behaviours'. $\mathrm{PhD}$ diss., Open University, 2007.

Peters, Gary. The Philosophy of Improvisation. Chicago: Chicago University Press, 2009.

Reber, Arthur. Implicit Learning and Tacit Knowledge: an Essay on the Cognitive Unconscious. Oxford: Oxford University Press, 1993.

Reinholdsson, Peter. Making Music Together: an Interactionist Perspective on Small-Group Performance in Jazz. Uppsala: Uppsala University Press, 1998.

Sawyer, Keith. 'Group Creativity: Musical Performance and Collaboration'. Psychology of Music 34/2 (2006), 14866.

— Psychology of Aesthetics 3/2 (2009), 81-92.

Schutz, Alfred. Collected Papers, vol. 2: Studies in Social Theory, ed. Arvid Broderson. The Hague: Martinus Nijhoff, 1964. 159-78.

Silverstein, Michael. 'The Improvisational Performance of Culture in Realtime Discursive Practice', in Creativity in Performance, ed. Keith Sawyer. Greenwich, CO: Ablex, 1997. 265-311.

_. 'Indexical Order and the Dialectics of Sociolinguistic Life'. Language and Communication 23 (2003), 193229.

Sternberg, Robert, and Joseph Horvath. Tacit Knowledge in Professional Practice: Researcher and Practitioner Perspectives. Mahwah, NJ: Lawrence Erlbaum Associates, 1999.

Toynbee, Jason. Making Popular Music: Musicians, Creativity and Institutions. London: Arnold, 2000. 